\title{
Frequency, causes and human impact of motor vehicle-related road traffic accident (RTA) in Lubumbashi, Democratic Republic of Congo
}

\author{
Luzitu Severin Nangana ${ }^{1} \cdot$ Ben Monga $^{1} \cdot$ Nlandu Roger Ngatu ${ }^{2} \cdot$ \\ Etongola Papy Mbelambela ${ }^{3} \cdot$ Lukuke Hendrick Mbutshu $^{1}$. \\ Kaj Francoise Malonga ${ }^{1}$
}

Received: 1 February 2016/Accepted: 25 April 2016/Published online: 4 May 2016

(c) The Japanese Society for Hygiene 2016

\begin{abstract}
Objectives Road traffic accident (RTA)-related trauma remains a public health issue. The aim of this study was to determine the frequency, causes and human impact of motor vehicle-related RTA in Lubumbashi, Democratic Republic of Congo.

Methods A prospective cross-sectional study was conducted in the first semester of the year 2015 in which 288 drivers (144 RTA-causing drivers and 144 control drivers who have been declared not guilty by road safety agents) involved in 144 motor vehicle-related RTA were interviewed, and only data on all RTA involving two motor vehicles with at least four wheels were recorded and analyzed.

Results Results showed a total of 144 RTA that involved two motor vehicles with four wheels occurring during the study period which affected 104 people, including 93 injury and 11 fatality cases. The mean age of RTA-causing drivers was $33.8 \pm 7.4$, whereas it was $35 \pm 8.8$ for control drivers. The majority of RTA-causing drivers (53.4\%) did not attend a driving school. Over speeding (32\%), distracted driving (22\%), overtaking (16\%) and careless driving/risky maneuver $(15 \%)$ and driving under the
\end{abstract}

Nlandu Roger Ngatu

doc.rogerngatu@gmail.com

1 Ecole de Santé Publique, University of Lubumbashi, Lubumbashi, Democratic Republic of the Congo

2 Graduate School of Health Sciences and Nursing, and Disaster Nursing Global Leading doctoral Program (DNGL), University of Kochi, Ike Campus. 2751-1 Ike, Office No C222, Kochi-city, Kochi prefecture 781-8515, Japan

3 Department of Environmental Medicine, Kochi University Medical School, Nankoku, Japan influence of alcohol (9\%) were the main causes of RTA occurrence. In addition, the absence of a valid driving license $[\mathrm{aOR}=12.74( \pm 2.71) ; 95 \%$ CI 3.877-41.916; $p=0.015]$, unfastened seat belt for the RTA-causing driver $\quad[\mathrm{aOR}=1.85 \quad( \pm 0.62) ; \quad 95 \%$ CI $1.306-6.661$; $p=0.048]$ and presence of damages on RTA-causing vehicle $[\mathrm{aOR}=33.56$ (24.01); $95 \%$ CI 1.429-78.352; $p=0.029]$ were associated with the occurrence of RTArelated fatality.

Conclusion This study showed a relatively high frequency of RTA occurring in Lubumbashi and suggests the necessity to reinforce road traffic regulation.

Keywords Distracted driving - Lubumbashi - Motor vehicle $\cdot$ Road traffic accident $\cdot$ Accident prevention

\section{Introduction}

Road safety and road traffic accident (RTA)-related trauma remain a public health issue in most developing countries, especially in Africa. Annually, RTA cause approximately $1,240,000$ deaths and 20-50 million cases of injury worldwide; the World Health Organization (WHO) estimates that, by the year 2020, there will be 1,900,000 deaths consecutive to RTA [1], whereas RTA-related injuries are estimated to be the fifth leading contributor to the global burden of disease by 2030 [2]. The human and economic impact of RTA in low and middle income countries is huge, as over $90 \%$ of fatal crashes occur there, with an annual cost of 65 billion US dollars [1, 3, 4].

In Africa, RTA represent a real burden besides other prevalent health issues, such as Malaria and HIV/AIDS, with a mortality rate $(28.3$ per 100,000$)$ higher than Europe (11.0 per 100,000); however, the number of studies 
conducted in this field is still insignificant for most SubSaharan African countries [5, 6]. Recent data from the 'national committee for road safety' showed that there were 2601 cases of motor vehicle accidents occurring in Kinshasa, the capital city of the Democratic Republic of the Congo (DRC) that caused 3070 injury cases and 215 deaths in the year 2001, whereas, in 2007, an increase of $58 \%$ occurred with a total of 4483 RTA, causing 5899 injury cases and 335 deaths in Kinshasa [7]. On national level, the World Health Organization (WHO) has estimated that the number of RTA-related deaths in DRC was 20,000 in 2009 and 10,000 in 2010 and reached 60,000 in 2012 [8].

To our best knowledge, there has been no follow-up research that investigated the scope and determinants of RTA in DRC. The purpose of the present study was to evaluate the frequency of RTA events and associated factors in Lubumbashi, the second town and economic capital of DRC.

\section{Materials and methods}

\section{Study design and sample}

A cross-sectional study was conducted in the first semester of the year 2015, in which information on all RTA occurring between April 1 and May 31, 2015 (2 months) was recorded. This was a collaborative work initiated by the School of Public Health, University of Lubumbashi, with the participation of the provincial offices of the national road traffic safety police and the national insurance company, known locally as police de circulation routiere (PCR) and societe nationale d'assurance (SONAS), respectively. Lubumbashi is a town located in the Katanga province, DRC, with an area of $747 \mathrm{~km}^{2}$ and a population of 1,718,661. It comprises six urban counties (Rwashi, Lubumbashi, Kamalondo, Kenya, Katuba and Kampemba) and one rural county (Annexes). During the study period, 217 RTA occurred in Lubumbashi causing 44 deaths. Of those RTA events, only accidents involving two motor vehicles with at least four wheels each (144 in total) were taken into account, given the high probability to get both drivers interviewed.

In this study, 288 drivers involved in 144 motor vehiclerelated RTA events participated in the interview (144 RTA-causing drivers and 144 control drivers who were declared not at fault by road traffic agents); they anonymously answered an interview questionnaire that comprised questions related to the characteristics of the drivers (gender, age, marital status, level of education, driving training and license), the vehicles involved (manufacturer, age, presence of seat belts, car insurance, position of the handle) and the RTA event (time and date of occurrence, cause of the accident, outcomes of the event in terms of injury or death, material damages). A team of three trained interviewers from the School of Public Health, University of Lubumbashi, and representative road safety policemen were in charge of conducting interviews whenever an RTA occurred. Collected information was chronologically and anonymously recorded in a prepared excel sheet.

\section{Ethical considerations and data analysis}

Ethical approval was obtained from the research ethics committee of the school of Public health, University of Lubumbashi; in addition, signed informed consent was obtained from drivers prior to the interview. Dependent variables were RTA events, injury and death, whereas driver's age, gender, training at driving school, driving license, car insurance, age of the vehicle, position of the handle (left/right), day of the week, time of the day and use of seat belt were considered independent variables. Data are presented as proportions and means. Chi-square test was performed to compare RTA proportions for dichotomized dependent variables, whereas multiple logistic regression test was used to assess associations between RTA-causing drivers/vehicles and control drivers/vehicles' characteristics and the occurrence of fatality. $p$ values less than 0.05 were considered significant. Collected data were analyzed with the use of Excel 2008 and Stata statistical package version 10 (Stata Corp., College Station, Texas, USA).

\section{Results}

\section{Characteristics of drivers and motor vehicles involved in road traffic accidents (RTA)}

In total, there were 144 RTA involving two motor vehicles with at least four wheels each. The mean age of RTAcausing drivers was $33.8 \pm 7.4$, whereas it was $35 \pm 8.8$ in the group of control drivers. The mean age of RTA-causing vehicles was $12.5 \pm 3.6$ (vs. $11.9 \pm 3.3$ for control vehicles), ranging from 4 to 26 years. The majority of RTA events occurred between 17:00 and 20:00 (30.9\%), followed by the time range 9:00-12:00 (19.8\%), 13:00-16:00 $(18.4 \%)$ and 21:00-24:00 (18.4 \%). There were less RTA events occurring early in the morning between 5:00 and 8:00 $(11.1 \%)$. Regarding the week days, a higher proportion of RTA events occurred on Saturdays, $20.1 \%$; followed by Monday (16.6\%), Wednesday (14.7\%), Tuesday $(13.8 \%)$, Thursday and Friday (11.9\%), whereas Sunday accounted for only $10.6 \%$ of RTA (Table 1).

The majority of RTA-causing drivers, $71.5 \%$, reported that they had no driving license; only $28.5 \%$ of drivers in 
Table 1 Characteristics of drivers/vehicles involved in RTA in Lubumbashi $(N=288)$

\begin{tabular}{|c|c|c|c|c|c|}
\hline \multirow[t]{2}{*}{ Characteristics } & \multicolumn{2}{|c|}{$\begin{array}{l}\text { RTA-causing } \\
\text { vehicle }\end{array}$} & \multicolumn{2}{|l|}{$\begin{array}{l}\text { Control } \\
\text { vehicle }\end{array}$} & \multirow[t]{2}{*}{$p$} \\
\hline & $n(144)$ & $\%$ & $n(144)$ & $\%$ & \\
\hline \multicolumn{6}{|l|}{ Drivers } \\
\hline \multicolumn{6}{|l|}{ Gender } \\
\hline M & 142 & $98.6^{\#}$ & 132 & 91.7 & 0.006 \\
\hline $\mathrm{F}$ & 2 & 1.4 & 12 & 8.3 & \\
\hline \multicolumn{6}{|l|}{ Age } \\
\hline Young ( $<25$ years) & 17 & 11.8 & 15 & 10.4 & 0.018 \\
\hline Old (25-61 years) & 127 & $88.2^{\#}$ & 129 & 89.6 & \\
\hline \multicolumn{6}{|l|}{ Marital status } \\
\hline Married & 80 & 55.6 & 68 & 47.2 & 0.177 \\
\hline Single & 55 & 38.2 & 70 & 48.6 & \\
\hline Divorced & 8 & 5.5 & 5 & 3.5 & \\
\hline Widow & 1 & 0.7 & 1 & 0.7 & \\
\hline \multicolumn{6}{|l|}{ Driving school } \\
\hline Yes & 67 & 46.6 & 83 & 57.6 & 0.063 \\
\hline No & 77 & 53.4 & 61 & 42.4 & \\
\hline \multicolumn{6}{|l|}{ Valid driving license } \\
\hline Yes & 41 & 28.5 & 44 & 30.6 & - \\
\hline No & 103 & $71.5^{\#}$ & 100 & 69.4 & 0.698 \\
\hline \multicolumn{6}{|l|}{ Vehicles } \\
\hline \multicolumn{6}{|l|}{ Car insurance } \\
\hline Yes & 111 & $77.1^{\#}$ & 103 & 71.5 & 0.422 \\
\hline No & 33 & 22.9 & 41 & 28.5 & \\
\hline \multicolumn{6}{|l|}{ Handle position } \\
\hline Left & 4 & 2.8 & 11 & 7.6 & 0.06 \\
\hline Right & 140 & $97.2^{\#}$ & 133 & 92.4 & \\
\hline \multicolumn{6}{|l|}{ Age of vehicle } \\
\hline$<10$ years & 37 & 26.1 & 33 & 22.9 & 0.583 \\
\hline 10 years or older & 105 & $73.9^{\#}$ & 111 & 77.1 & \\
\hline \multicolumn{6}{|l|}{ Damaged } \\
\hline Yes & 130 & $91.2^{\#}$ & 132 & 91.7 & 0.838 \\
\hline No & 14 & 9.8 & 12 & 8.3 & \\
\hline
\end{tabular}

$p, p$ value when comparing RTA-causing drivers/vehicles to control drivers/vehicles, $R T A$ road traffic accident, $n$ number, $\%$, percentage, $y$ year

\# $p<0.001$ when comparing categories of RTA-causing drivers/vehicles' characteristics

this group had a driving license without attending a driving school. Approximately, a quarter of vehicles driven by RTA-causing drivers and control drivers had no insurance, 22.9 and $28.5 \%$, respectively (Table 1 ). Though traffic regulation in the country suggests that people should drive on the right side of the road, most vehicles involved in RTA during the study period were right handled, 97.2 and $92.4 \%$, for RTA-causing vehicles and control vehicles, respectively (Table 1).

\section{Causes, human impact of RTA and factors associated with RTA occurrence and RTA-related fatality in Lubumbashi, 1 May-30 April, 2015}

Figure 1 shows the distribution of RTA events according to the cause. A high proportion of RTA events occurred due to over speeding (32\%), followed by distracted driving (text messaging, phone call, chatting; $22 \%$ ), overtaking $(16 \%)$ and careless driving/risky maneuver $(15 \%)$ and driving under the influence of alcohol $(9 \%)$. Low visibility, and technical problem accounted each for five or less RTA events each (Fig. 1). When considering the responsibility for the crash, it was found that the RTA-causing drivers were responsible in $98 \%$ of RTA events, whereas technical problem accounted only for $2 \%$.

The human impact of motor vehicle related RTA was not negligible, with 104 victims in total, including 93 injury cases and 11 deaths. For RTA-causing motor vehicles, there were 35 victims including $15 \%$ of those who suffered moderate injury cases, $6 \%$ of severe injury cases, $1 \%$ of very severe injury cases and $2 \%$ of fatalities. On the other hand, control vehicle passengers were the most affected with 69 victims, including $6 \%$ of fatalities (deaths), $17 \%$ of severe injury, $11 \%$ of very severe injury cases and $14 \%$ of moderate injury cases. Regarding RTArelated material damages, $92 \%(132 / 144)$ of control vehicles were damaged (including $22 \%$ of cases of severely damage). On the other hand, $91.2 \%$ (130/144) of RTA-causing vehicles suffered damages $(6 \%$ of which were severely damaged) (not shown).

This study also showed that the absence of a valid driving license for RTA-causing drivers [aOR 12.74 $( \pm 2.71) ; 95 \%$ CI 3.877-41.916; $p=0.015]$, unfastened seat belt for the RTA-causing driver [aOR $1.85( \pm 0.62)$; $95 \%$ CI 1.306-6.661; $p=0.048]$ and the presence of damages on RTA-causing vehicle [aOR $=33.56$ (24.01); $95 \%$ CI 1.429-78.352; $p=0.029$ ] were associated with the occurrence of RTA-related fatality (Table 2).

\section{Discussion and conclusion}

This study investigated the causes and factors associated with RTA in Lubumbashi, DRC. It was found that 144 RTA involving two motor vehicles with at least four wheels each. Over speeding, distracted driving (text messaging, calling on phone, chatting), overtaking, careless driving/risky maneuver and driving under the influence of alcohol were most prevalent causes of RTA occurrence. Other causes included low visibility and technical problem. In Kenya, a recent observational study on road safety status showed that $34 \%$ of RTA were caused by high speed in Naivasha municipality, Nakuru County, whereas a higher 


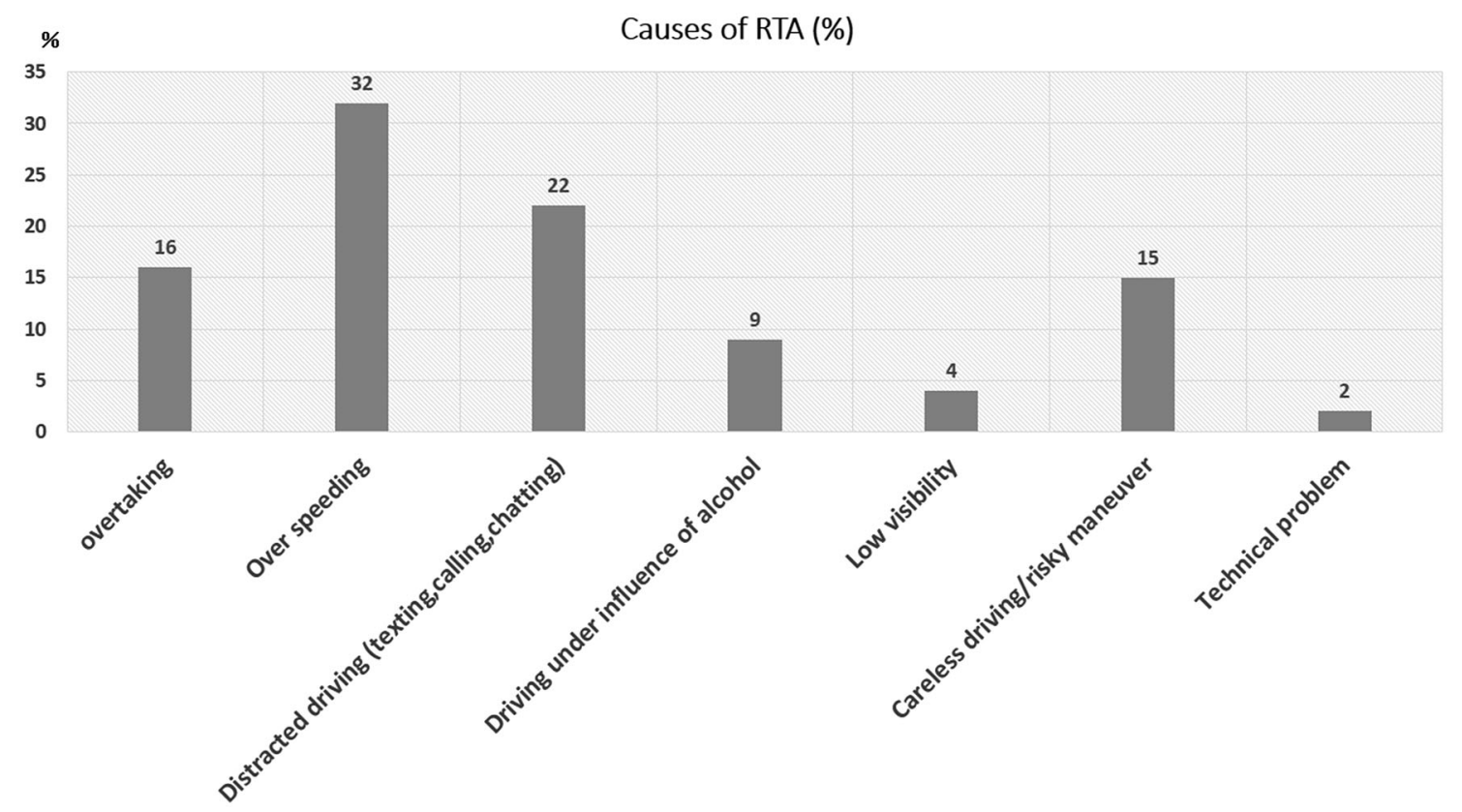

Fig. 1 Causes of road traffic accidents occurring in Lubumbashi (1

(text messaging, calling, chatting; $22 \%$ ), overtaking (16\%), careless April-31 May, 2015). It shows different causes of road traffic driving/risky maneuver $(15 \%)$ and the influence of alcohol $(9 \%)$. accidents (RTA) in Lubumbashi; a higher proportion of RTA events was caused by over speeding (32\%), followed by distracted driving

Other causes, such as low visibility and technical problem, accounted for less than $5 \%$ each
Table 2 Factors associated with the occurrence of road traffic accident-related fatalities in Lubumbashi

\begin{tabular}{lrrrc}
\hline Characteristics of drivers/vehicles & aOR & SE & $95 \%$ CI & $p$ value \\
\hline Drivers & & & & \\
Gender of driver 1 (male vs. female) & 4.31 & 2.46 & $0.229-8.135$ & 0.329 \\
Driving training/driver 1 (no vs. yes) & 1.17 & 0.36 & $0.026-1.178$ & 0.064 \\
Valid license holder/driver 1 (no vs. yes) & 12.74 & 2.71 & $3.877-41.916$ & 0.015 \\
Seat-belt not/driver 1 (unfastened vs. fastened) & 1.85 & 0.62 & $1.306-6.661$ & 0.048 \\
Seat-belt/driver 2 (unfastened vs. fastened) & 0.07 & 0.10 & $0.005-1.067$ & 0.078 \\
Vehicles & & & & \\
Handle position/vehicle 1 (right vs. left) & 0.12 & 0.03 & $0.034-0.148$ & 0.067 \\
Handle position vehicle 2 (right vs. left) & 0.22 & 0.01 & $0.042-0.113$ & 0.743 \\
Damaged vehicle 1 (yes vs. no) & 33.56 & 24.01 & $1.429-78.352$ & 0.029 \\
Damaged vehicle 2 (yes vs. no) & 0.51 & 0.32 & $0.068-3.688$ & 0.502 \\
Age of vehicle 1 (over 10 vs. 10 y or less) & 0.97 & 0.12 & $0.754-1.248$ & 0.875 \\
Age of vehicle 2 (over 10 vs. 10 y or less) & 0.74 & 0.13 & $0.518-1.077$ & 0.119 \\
\hline
\end{tabular}

$a O R$ adjusted odds ration, $S E$ standard error, $C I$ confidence interval, driverl the driver who caused the accident, driver 2 the driver of the vehicle that was hit (control driver), vehicle1 the vehicle of the accidentcausing driver, vehicle 2 the vehicle that was hit (control vehicle), $y$ years proportion (69\%) was found in Thika area [9]. In our study, over speeding was implicated in the occurrence of nearly one-third (32\%) of RTA events.

The previous reports have suggested that younger age constitutes a risk factor for RTA [10,11]. For example, in the US, younger age (15-20 years) has been reported to account for $10 \%$ of all motor vehicle traffic deaths and $14 \%$ of crashes resulting in injury in the US [12]. In our study, in contrast, older age (over 25 years) was associated with RTA. In fact, of the RTA-causing drivers, there were only $12 \%(18 / 144)$ who were young (25 years or less) of whom only $5 \%(1 / 144)$ got injured. This situation may be due to the very low number of teenagers who drive in DRC.

Distracted driving, particularly calling and text messaging while driving, has recently been recognized as an illegal act that threatens road traffic safety in many 
countries. Asbridge and colleagues [13] reported an increase of $70 \%$ in odds of culpable crash for drivers who use cell phone, as compared to those who do not use such a device while driving. In addition, a meta-analysis of epidemiological studies on road crash and mobile phone use found that cell phone use increased the odds of a crash by 2.8 [14]. Other estimated based on the records of mobile phone use among drivers have shown an increase of the risk of road crash by a factor of $4[15,16]$. Our study showed that $22 \%$ of RTA events were related to distracted driving, which was the second cause of RTA.

Moreover, this study showed that, within the twomonth period of study, there were 11 fatality cases related to motor vehicle-caused RTA events. A multivariate analysis showed that the risk for RTA to result in a fatality was 12.7 times higher when the RTA-causing driver had no valid driving license, 1.8 times higher when the latter driver did not fasten his/her seat belt and 33.5 times higher when the RTA-causing vehicle was damaged as a consequence of the accident. This may suggest that subjects who have not been properly trained, lacking appropriate driving skill, and those who lack compliance to traffic rules related to seat belt fastening and speeding are susceptible to cause RTA, in Lubumbashi particularly. As for many developing countries where most populations live with a very low socioeconomic status, there is dysfunction of public services, including the police and the general public administration services. The road safety agency issues traffic rules, but their applications are not reinforced. For example, driving schools are mainly businesses ran by individuals, and they are rarely regulated. Thus, there are still weaknesses in terms of application and compliance to road safety rules. Sometimes, people in need of a driving license may purchase it prior to attending a driving school. Blood alcohol level is rarely checked and drinking an alcoholic beverage before driving is not generally considered a breach to the road safety law, particularly for commercial drivers.

The present is limited by the relatively short period of the study implementation. This fact is, at least, due to the long preparation time, as we needed to get both the provincial road safety and insurance agencies involved in the study and establish a collaborative research team to carry out the study project within a single academic year. Another fact is that in this study, only RTA involving two motor vehicles were taken into account. There are some practical reasons. First, according to our study protocol, the pair of drivers involved in a RTA should be interviewed and the responsibility in RTA occurrence established by the road safety police. The driver whose vehicle was hit was considered a 'control driver' in the study. In fact, reports from the road safety police in Lubumbashi suggested that there is a low probability to have an RTAcausing driver interviewed when the accident involved a pedestrian; however, in the case of two motor vehicles, both drivers are mostly heard by the police, and it was indispensable for our study that the questionnaire be answered by drivers to meet the study objectives. Future studies with a longer time period of implementation and a bigger sample size should be envisaged.

Furthermore, it could have been informative in this study to analyze the relationship between handle position and RTA, given that a new Congolese road traffic regulation law suggested the prohibition of import of right-handled vehicles. However, as almost all RTA-causing motor vehicles were right-handled and more than $70 \%$ of RTAcausing automobiles were old (over 10 years), possibly due to the low economic status of the majority of Congolese people, an attempt to draw conclusions on the high proportion of right-handled vehicles and old ones that were involved in RTA would probably lead to a misinterpretation of the findings. A more elaborated long-term prospective study with a bigger sample size might provide more insights on such relationships. Nevertheless, this study is the first prospective research to be conducted in DRC, as well as the first to investigate the causes and evaluate the human impact of RTA in the country. Information provided in this paper can serve as a basis for future research projects on RTA in DRC.

As a conclusion, the present study highlights the causes and predictors of RTA in Lubumbashi, suggesting the necessity for reinforcement of road traffic regulation and preventive safety measures mainly targeting high risk behaviors, such as over speeding, sleepiness, distracted driving (phone call, text messaging) and driving under the influence of alcohol or drug.

Acknowledgments The authors thank all the staff of the offices of the national insurance company (SONAS) and national road safety police, Lubumbashi, Democratic Republic of the Congo for their wonderful support.

\section{Compliance with ethical standards}

Conflict of interest The authors declare no conflict of interest related to this study.

\section{References}

1. World Health Organization (WHO). Global status report on road safety 2013. WHO, 2013. Available at: URL:. www.who.int/vio lence_injury_prevention/road_safety_status/2013/en/.

2. Maters CD, Loncar D. projections of global mortality and burden of disease from 2002 to 2030. Plos Med. 2006;3(11):e442.

3. Ameratunga S, Hijar M, Norton R. Road traffic injuries: confronting disparities to address a global-health problem. Lancet. 2006;367(9521):1533-40. 
4. Herman J, Ameratunga S, Jackson R. Burden of road traffic injuries and related risk factors in low and middle-income pacific island countries and territories: a systematic review of the scientific literature (TRIP 5). BMC Public Health. 2012;12:479.

5. Lagarde E. Road traffic injury is an escalating burden in Africa and deserves proportionate research efforts. Plos Med 2007; 4(86): e170.

6. Peden M, Scurfield R, Sleet D, Mohan D, Hyder AA, Jarawan E, Mathers C. World report on road traffic injury prevention. Geneva: World Health Organization; 2004. Available at: http://www. who.int/world-health-day2004/infomaterial/world_report/en/.

7. Mungazi W. Bas-Congo: la route tue plus que le SIDA. Infos Bas-Congo News, 2008. http://www.infobascongo.net/beta/?p= 1608.

8. Asumani MZ. Le taux d'accidents de circulation augmente a Kinshasa (Article in French). Available at: https://transurbain kinshasa.wordpress.com/2013/06/27/le-taux-daccidents-de-circu lation-augmente-a-kinshasa/.

9. Bachani AM, Koradia P, Herbert HK, Mogere S, Akungah D, Nyamari J, Osoro E, Maina W, Stevens KA. Road traffic injuries in Kenya: the health burden and risk factors in two districts. Traffic Inj prev. 2012;13(1):24-30.

10. National Highway Traffic Safety administration. Traffic safety facts: young drivers (technical report no DOT HS 811 622). Washington, DC; 2012.
11. Senserrick TM. Reducing young driver road trauma: guidance and optimism for the future. Inj Prev. 2006;12(1):i56-60.

12. Klauer SG, Guo F, Simons-Morton BG, Ouimet MC, Lee SE, Dingus TA. Distracted driving and risk of road crashes among novice and experienced drivers. New Engl J Med. 2013;370: 54-9.

13. Asbridge M, Brubacher JR, Chan H. Cell phone use and traffic crash risk: a culpability analysis. Int J Epidemiol. 2013;42: 259-67.

14. Elvik E. The effects on accident risk of using mobile phones: problems of meta-analysis when studies are few and bad. In: Safety data, analysis, and evaluation, vol. 1. Washington, DC: Transportation Research Board, 2011, p. 20-26.

15. McEvoy SP, Stevenson MR, McCartt AT, Woodward M, Haworth C, Palamara P, Cercarelli R. Role of mobile phones in motor vehicle crashes resulting in hospital attendance: a casecrossover study. BMJ. 2005;331:428-30.

16. Hosking SG, Young KL, Regan MA. The effects of text messaging on young novice driver performance. Report No 246. Melbourne, VIC, Australia: National Roads and Motorists' Association Motoring and Services and National Roads and Motorists' Association Insurance, 2006. 